\title{
Reduction of Reactive Power Waste of Inductive Electrical Appliances using Power Factor Correction
}

\author{
M.M.P.M. Fernando ${ }^{1 *}$, D.D.A. Gamini ${ }^{2}$ and J.A.L. Naveendra ${ }^{1}$ \\ ${ }^{1}$ Department of Physics, University of Sri Jayewardenepura, Nugegoda, Sri Lanka \\ ${ }^{2}$ Department of Computer Science, University of Sri Jayewardenepura, Nugegoda, Sri Lanka
}

Date Received: 04-01-2021 Date Accepted: 15-01-2021

\begin{abstract}
Electricity is the primary source of power in most countries including Sri Lanka, and saving or minimising the waste of it has become crucial in facing the world power crisis. Electrical power is wasted in various ways including reactive power waste due to induction and capacitance of appliances, and standby power loss. These two contribute most to the waste. This paper focuses on reducing the reactive power waste of inductive electrical appliances commonly used in home and office by increasing the power factor. An attempt was made to reduce the power waste of inductive electrical appliances by connecting a capacitor bank with a variable capacitance in parallel with the appliance. Optimal capacitance and the power factor are determined using the capacitor bank. Results indicate about 30 percent of power saving could be achieved for fluorescent tube lamps using a power factor correction. A maximum power factor of 0.93 is achieved at the capacitance value of $2.99 \mu \mathrm{F}$. It is not possible, by this method, to increase the power factor of more capacitive equipment such as CFL bulbs and ceiling fans. In this case, power minimisation could be tried connecting inductors in parallel with the equipment. Power factor and power consumption of home electrical appliances were measured for advising the general public of high power consuming equipment, especially in stand-by mode. To attain a further reduction of power waste it is proposed to measure inductance, capacitance and resistance of appliances using Hendry, Farad and Ohm meter. Total impedance can then be calculated and the power waste could be minimised using appropriate capacitors and/or inductors.
\end{abstract}

Keywords: reactive power, power factor, power waste, reactive power waste, power minimisation

\section{Introduction}

Today, electricity has become the primary source of power for most countries in the world including Sri Lanka. Saving of electrical power or minimising the waste of is very crucial today in facing the world power crisis. Manufactures of electrical equipment are making their way to design their products in such a way they consume less power. Before thousands of years, the scientists all over the world were fascinated by lightning. Some of them wondered how to put that kind of energy in to practical use. In 1752, a famous scientist, Benjamin Franklin proved that the lightning was electrical current (History.com Editors, 2020), but the path to the everyday use of electrical power was not a success until the $18^{\text {th }}$ century. In 1820, Hans Christian Oersted discovered that the electrical current creates a magnetic field (American Physical Society, 2008). In 1879, Thomas Edison invented the light bulb powered by the electrical current (The Franklin Institute, 2020), and produced a reliable long lasting source of light. At that time, the idea of lighting using electrical current was not new, but there were no appliances developed that was practical enough for home use. Edison not only developed the electrical light bulb, but an electrical lighting system that contains the all the necessary components to make electrical lighting safe, economical and practical. Edison, in 1882, switched on the world first electrical power distribution system, which was named as

*Correspondence: pmadhuranga@sjp.ac.lk

Tel: +94714478729

(C) University of Sri Jayewardenepura 
“Thomas Edison's Pearl Street Electricity Generating Station” (Davis, 2003). In the late 1800's, Nikola Tesla started to work with the generation and transmission of the alternating current (AC) electricity. Tesla, with the help of Westinghouse, introduced indoor lighting to our homes and to industrial machines (History.com, 2019).

It is important to know how the electrical power is wasted in order to effectively use it and to minimise the waste of it. Electrical power is wasted in various ways when using home and office electrical appliances. These include reactive power waste due to induction and capacitance of appliances, and standby power loss. The reactive power is known as the wasted power of the circuit. Reactive loads such as inductors and capacitors dissipate zero average power, yet the fact that they drop voltage due to the reactance and draw current gives the deceptive impression that they actually do dissipate power. This reactive power is defined as the time average of the instantaneous product of voltage and current which are with the phase difference of $90^{\circ}$ angle in between them. This paper mainly focuses on reducing the reactive power waste of inductive electrical appliances commonly used in home and office by increasing the power factor. The total impedance $(Z)$ of a circuit can be expressed as $Z=R+i\left(X_{L}-X_{C}\right)$, where $i=\sqrt{-1}$ and $R, X_{L}$ and $X_{C}$ are resistance, inductive reactance and capacitive reactance respectively. When the magnitudes of $X_{L}$ and $X_{C}$ are equal, the total impedance of the circuit is reduced to its minimum value $R$ according to the above equation. Thus, if the component is more inductive (i.e. $Z=R+i X$ ) a capacitor with the capacitive reactance $X_{C}=X$ can be connected or if the component is more capacitive (i.e. $Z=R-i X$ ), an inductor with the inductive reactance $X_{L}=X$ can be connected making the component purely resistive $(Z=R)$, which means the power factor of the component is increased to 1.0, which is the main theoretical aspect governing this paper.

Researches are being carried around the globe in this regard on the minimisation of reactive power waste. Reduction of reactive power in three-phase electric arc furnace was tried by Wolf and Thamodharan (Wolf and Thamodharan, 2000). They found a way to increase the dynamic performance of the furnace keeping the reactive power consumption at a constant level by adding a power controller and a booster transformer to the power source. Tanaka et al. (2014) proposed a simple reactive power control strategy for reducing the capacity of smart chargers used for electrical vehicles in Japan. Their strategy was based on the constant dc-capacitor voltage control of the grid-connected rectifier. According to their results, the capacity of the smart charger was reduced by $36 \%$. An integer programming based energy management system has been developed (Golshannavaz, 2018) for home users to reduce their monthly electricity bills by improving the power factor of connection between home and power supply grid. The system could help subscribers to manage their electrical equipment and components.

\section{Materials and Methods}

\subsection{Measure of power consumption}

All electrical appliances in the home were listed. RMS voltage, RMS current, real power (in watts), frequency of the supply current and power factor of all the electrical appliances in the home were measured using two separate portable power meters. Electrical appliances in the Department of Physics, University of Sri Jayewardenepura (except those in the office of the head of the department) were listed and all the measurements mentioned above were taken by the same power meters.

\subsection{Categorisation of measurements}

The data obtained were categorised by the types of the electrical appliance. The data then were analysed and compared within each category (fans, lights...etc.) in order to get an idea about the power consumption of electrical appliances in each category, at home and at the Department of Physics. 


\subsection{Power wastage minimisation process}

Step 1: RMS voltage, RMS current, real power, reactive power, apparent power and power factor of a $4 \mathrm{ft}$ tube light were measured using the Hammeg bench power meter.

Step 2: $\quad$ The $4 \mathrm{ft}$ tube light was replaced with another $4 \mathrm{ft}$ tube light and the Step 1 was repeated. This process was repeated and readings related to four tube lights were taken.

Step 3: The Step 1 and Step 2 were repeated for $2 \mathrm{ft}$ tube light, Philips $18 \mathrm{~W}$ CFL bulb and $60 \mathrm{~W}$ filament light bulb.

Step 4: The circuit shown in Figure1 was constructed to minimise the power wastage of the electrical appliances.

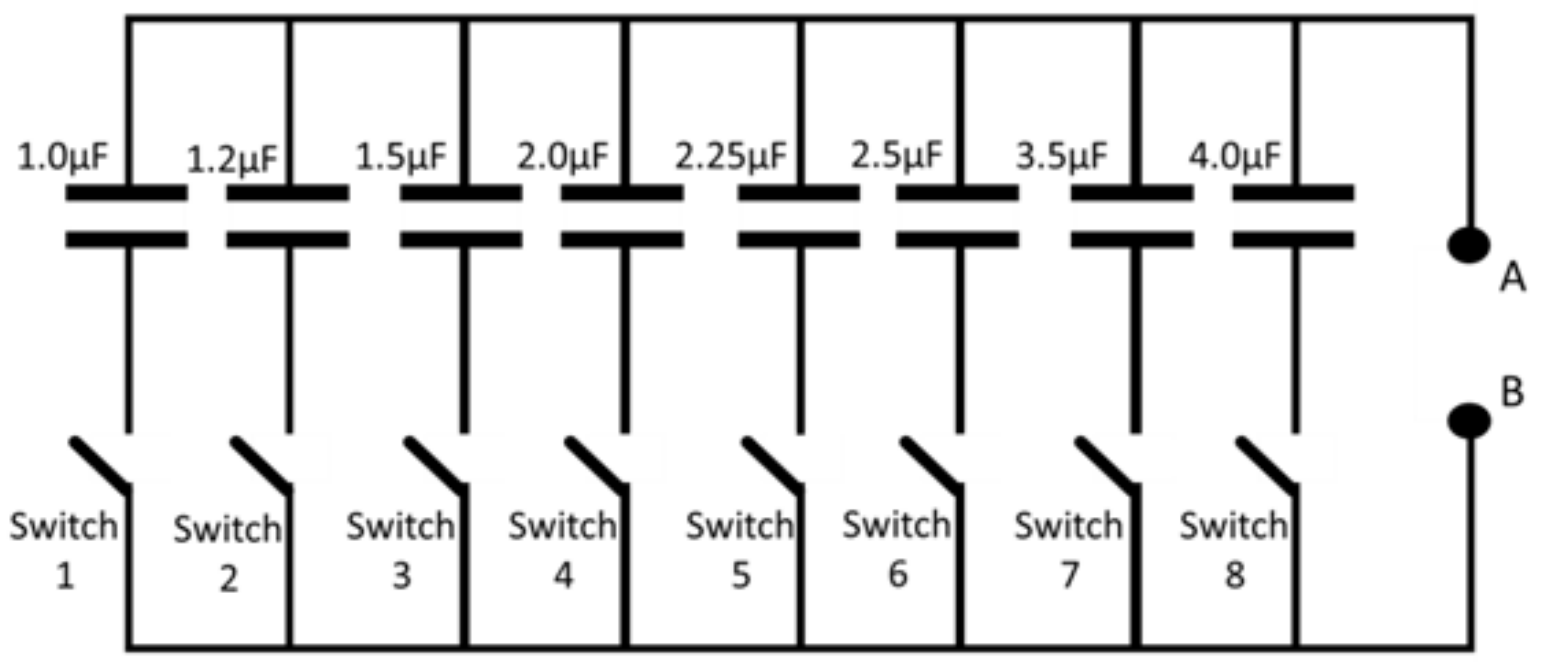

Figure 1. Power minimisation capacitor identification circuit.

Step 5: The constructed circuit was connected to the $4 \mathrm{ft}$ tube light with parallel connection using $\mathrm{A}$ and $\mathrm{B}$ connectors.

Step 6: RMS voltage, RMS current, real power, reactive power, apparent power and power factor measurements were taken by selecting $1.0 \mu \mathrm{F}$ mode (Switch 1 is closed while other switches are open) in the circuit.

Step 7: Step 6 was repeated for total capacitance with the values of $1.2 \mu \mathrm{F}, 1.5 \mu \mathrm{F}, 2.0 \mu \mathrm{F}, 2.25$ $\mu \mathrm{F}, 2.5 \mu \mathrm{F}, 3.0 \mu \mathrm{F}, 3.2 \mu \mathrm{F}, 3.5 \mu \mathrm{F}, 3.7 \mu \mathrm{F}, 4.0 \mu \mathrm{F}, 4.2 \mu \mathrm{F}, 4.5 \mu \mathrm{F}, 4.75 \mu \mathrm{F}$ and $5.0 \mu \mathrm{F}$.

Step 8: Steps 5-7 were repeated four times for different $4 \mathrm{ft}$ tube lights of the same brand.

Step 9: The most effective and practical capacitance value for the power wastage minimisation was attempted to be identified.

Step 10: Then the power factor readings were plotted against the capacitor values which were connected in parallel connection.

Step 11: Appropriate models/polynomial functions (with order 2 to order 10) were fitted to the data.

Step 12: The theoretical optimal capacitance value was determined for each device using the models fitted.

Step 13: Steps 5-12 were repeated for the $2 \mathrm{ft}$ tube light, $18 \mathrm{~W}$ CFL bulb and a ceiling fan.

\section{Results and Discussion}

Reduction of the power wastage was tried with a $4 \mathrm{ft}$ tube light using a high voltage (400 v) electrolytic capacitor with parallel connection. The capacitor was heated blown. The AC changes its 
polarity all the time and the electrolytic capacitor has a fixed polarity. This mismatch should be the reason behind the blown capacitor. A serial connection was also tried, and the capacitor was heated but the bulb was not powered on. It was hypothesised that the heating in the presence of serial capacitor could be due to high current flow through the circuit and the serial capacitor with bulb might have acted as a voltage divider which in turn had prevented the bulb from acquiring the necessary voltage.

Minimisation of power wastage was tried using the capacitor bank with variable capacitance (Figure 1). The summary of the results obtained for $4 \mathrm{ft}$ tube light, $2 \mathrm{ft}$ tube light and CFL bulb are shown in Figure 2-4. It is evident from Figure 2 that the power factor $(P F)$ for $4 \mathrm{ft}$ tube light can be described by a polynomial of the capacitance value $(x)$. After trying several possible models, it was found that the model: $P F=0.57895+0.17708 x-0.0066177 x^{3}$ fits the data well with $93 \%$ of the total variation in $P F$ explained by $x$ and $x^{3}$. The maximum power factor that could be attained is 0.932 at the optimal capacitance value of $2.987 \mu \mathrm{F}$. Similar results (Figure 3) are obtained for $2 \mathrm{ft}$ tube light, and the model that best fits the data is $P F=0.37261+0.20841 x-0.0074929 x^{3}$. Here also $93 \%$ of the total variation in data is explained by the predictors. The optimal value of the capacitance is $3.08 \mu \mathrm{F}$ with a maximum power factor of 0.80 .

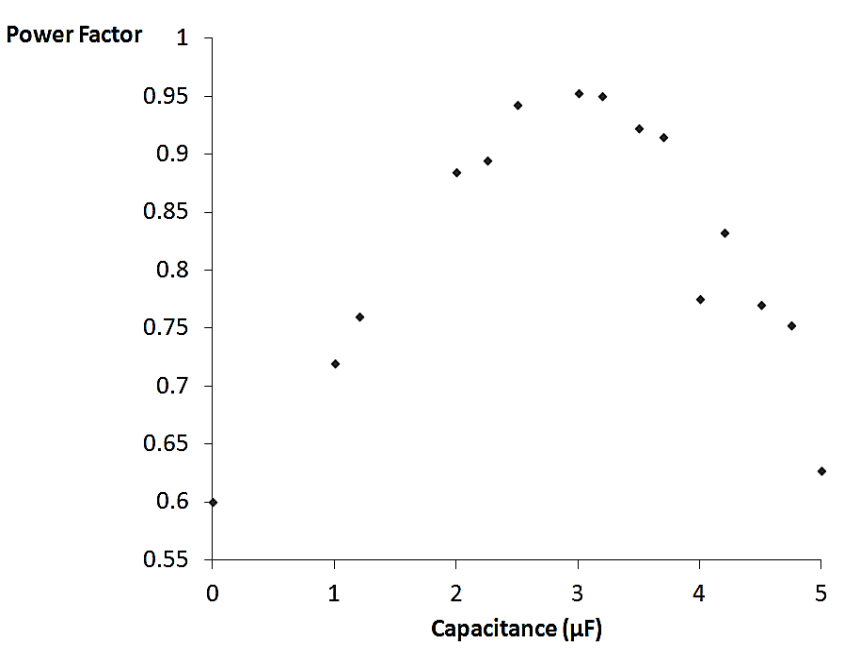

Figure 2. Power factor vs. capacitance for $4 \mathrm{ft}$ tube light.

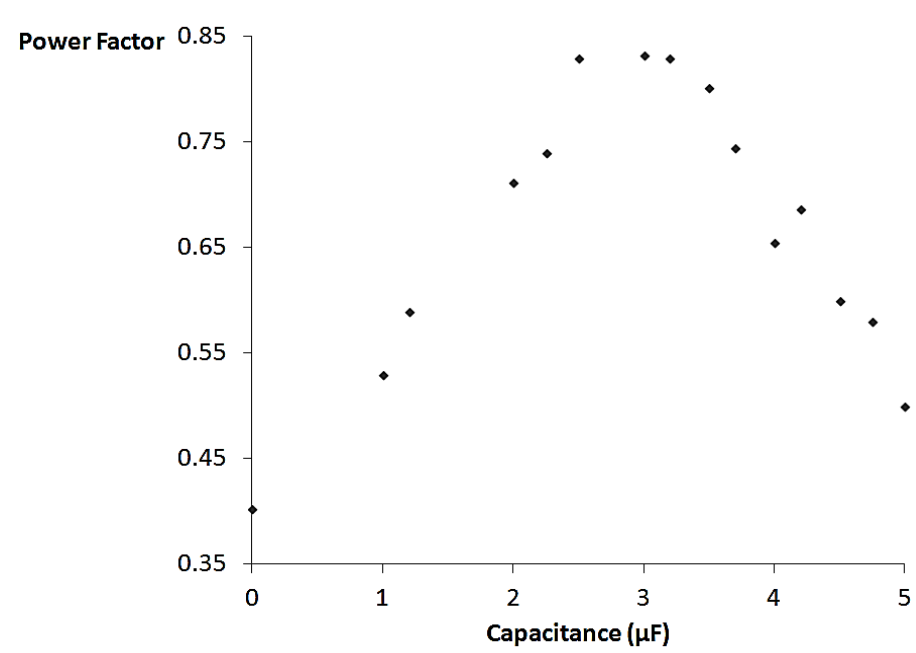

Figure 3. Power factor vs. capacitance for $2 \mathrm{ft}$ tube light.

Figure 4 reveals that power factor cannot be increased for CFL bulb with any capacitor in parallel connection. CFL bulb is more capacitive and hence the reduction of power wastage could be tried using inductors with parallel connection. It was observed that the maximum power factor for ceiling fan, which is almost 1.0, is attained when it is operating at the highest speed without any capacitor connected to it (Figure 5). Actually, there is a capacitor connected in parallel with the motor internally. The value of the capacitance has been chosen to maximise the power factor when the fan is operating at the highest speed. But this optimal value of the capacitance is not suitable for other speeds (Figure 6-9). Power factor for these speeds could be increased by disconnecting the internal capacitor and then trying out the experiment. 


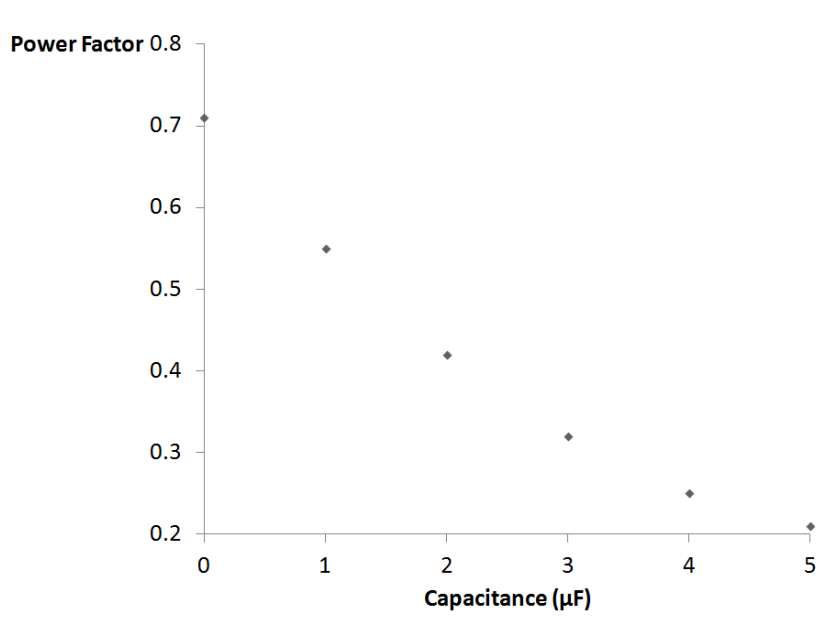

Figure 4. Power factor vs. capacitance for CFL bulb.

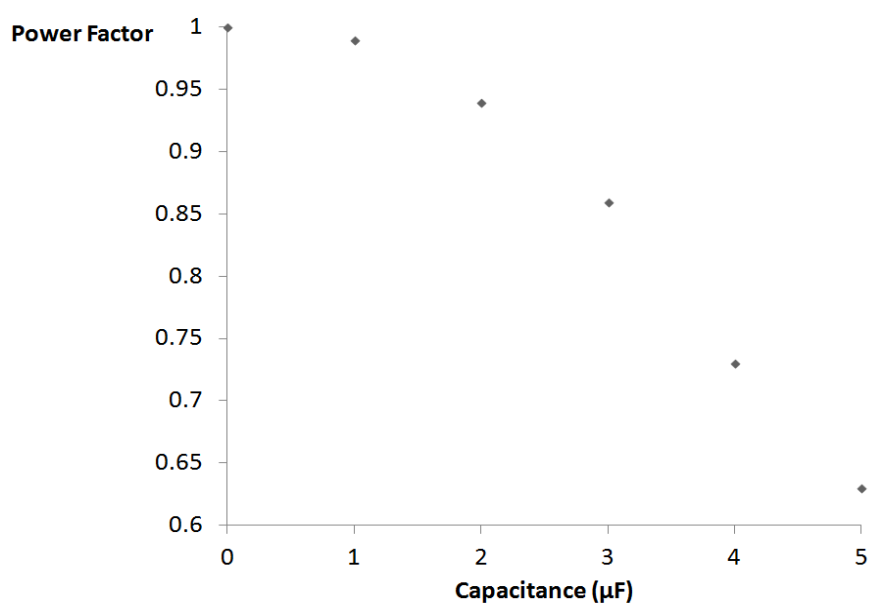

Figure 5. Power factor vs. capacitance for ceiling fan at speed 5 .

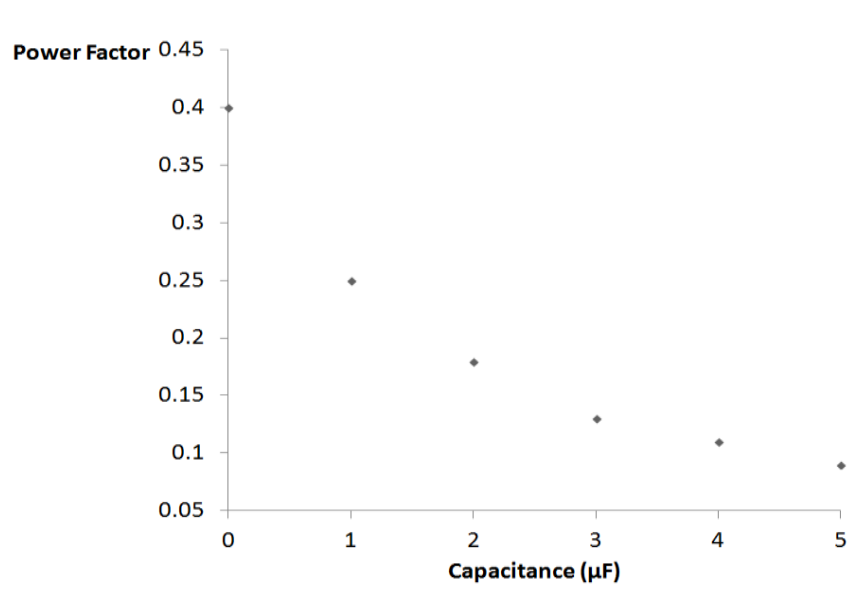

Figure 6. Power factor vs. capacitance for ceiling fan at speed 1 .

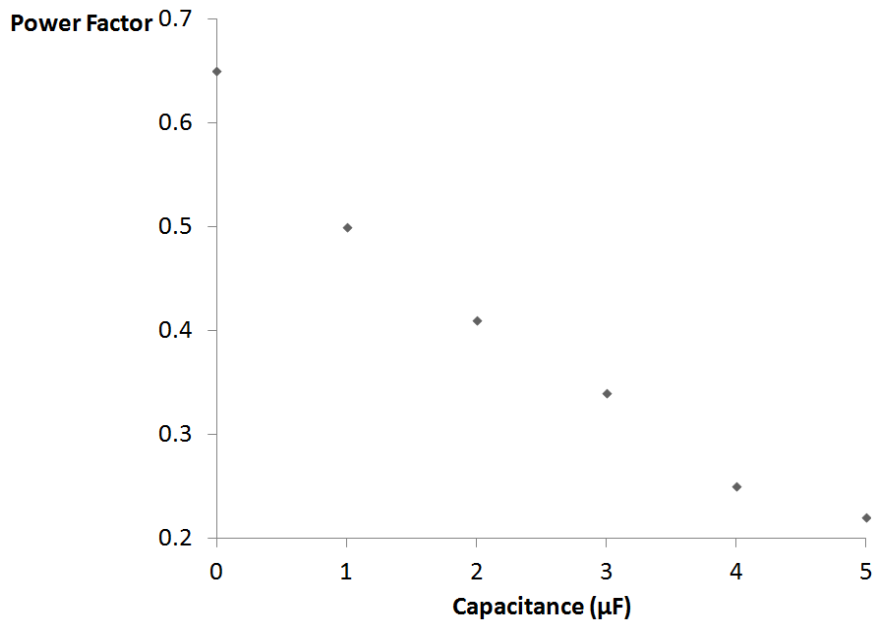

Figure 8. Power factor vs. capacitance for ceiling fan at speed 3 .

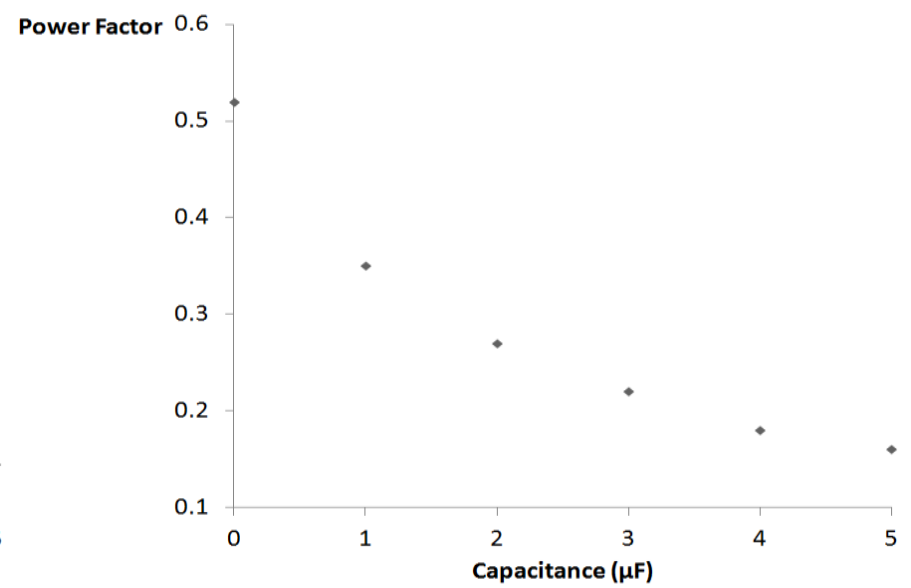

Figure 7. Power factor vs. capacitance for ceiling fan at speed 2 .

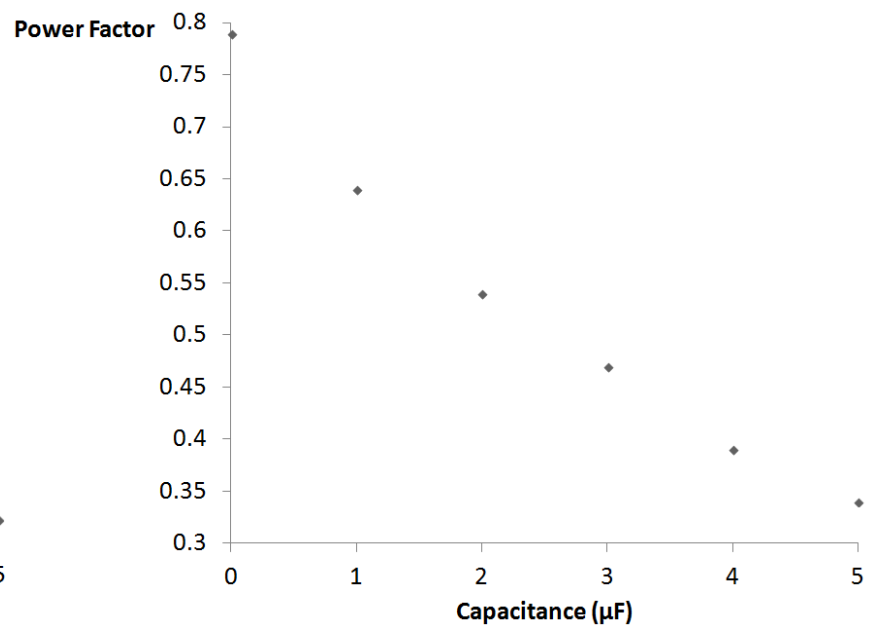

Figure 9. Power factor vs. capacitance for ceiling fan at speed 4 . 
Based on the data obtained for typical household appliances, UPS (uninterrupted power supply), desktop computers, old hi-fi setups and CRT TVs and satellite TV set top boxes consume a considerable amount of power in stand-by mode. Further, branded appliances tend to consume less power compared to unbranded/generic counterparts in operational mode.

\section{References}

American Physical Society, 2008. This Month in Physics History. American Physical Society. https://www.aps.org/publications/apsnews/200807/physicshistory.cfm Accessed 30 December 2020.

Davis, L.J., 2003. Fleet Fire: Thomas Edison and the Pioneers of the Electric Revolution. Arcade Publishing, New York.

Golshannavaz, S., 2018. Cooperation of electric vehicle and energy storage in reactive power compensation: An optimal home energy management system considering PV presence. Elsevier: Sustainable Cities and Society, 39:317-325.

History.com Editors, 2020. Benjamin Franklin flies kite during thunderstorm. A\&E Television Networks. https://www.history.com/this-day-in-history/franklin-flies-kite-during-thunderstorm. Accessed 30 December 2020.

Nix, E., 2019. How Edison, Tesla and Westinghouse Battled to Electrify America. A\&E Television Networks. https://www.history.com/news/what-was-the-war-of-the-currents. Accessed 30 December 2020.

Tanaka, H., Tanaka, T., Yamada, H. and Okamoto, M. 2014. Novel reactive power control strategy based on constant DC-capacitor voltage control for reducing the capacity of smart charger for electric vehicles on single-phase three-wire distribution feeders. 2014 International Power Electronics and Application Conference and Exposition, Shanghai, pp. 726-732.

The Franklin Institute, 2020. Edison's Lightbulb. The Franklin Institute. https://www.fi.edu/historyresources/edisons-lightbulb. Accessed 30 December 2020.

Wolf, A. and Thamodharan, M., 2000. Reactive power reduction in three-phase electric arc furnace. IEEE Transactions on Industrial Electronics, 47:729-733. 